Duguid, J. P. (1959). J. gen. Micrabiol. 21, 271-286

\title{
Fimbriae and Adhesive Properties in Klebsiella Strains
}

\author{
By J. P. DUGUID \\ Bacteriology Department, University of Edinburgh
}

SUMMARY: Fimbriae were found in 125 of 154 non-motile Klebsiella strains examined by electron-microscope in serial aerobic broth cultures. Fimbriate strains occurred in each of the capsule serotypes 1-72 and mostly showed the biochemical reactions of saprophytic Klebsiella aerogenes. The fimbriae were clearly distinguishable from the capsules and occurred also in non-capsulate mutants. Most fimbriate strains showed evidence of varying reversibly between a fimbriate and a non-fimbriate phase. The proportion of bacilli with fimbriae was greatest in broth cultures and was decreased, though never eliminated, by serial cultivation on nutrient agar. All 29 permanently non-fimbriate strains belonged to serotypes 1-6 and showed biochemical reactions common in pathogenic $K$. pneumoniae, $K$. ozaenae and $K$. rhinoscleromatis strains (anaerogenic, methyl-red positive, non-citrate utilizing or nonlactose fermenting). They differed from the fimbriate strains in growing less abundantly and usually in failing to form a pellicle on broth.

All the fimbriate strains, but none of the non-fimbriate, showed one or other or both of two kinds of adhesive property : one attributed to an 'MS adhesin', susceptible to inhibition by $D$-mannose and associated with a thick variety of fimbriae; the other due to an 'MR adhesin', resistant to mannose and associated with thinner fimbriae. Bacilli with MS adhesin rapidly adhered to red blood cells of the guinea-pig and other animals, except the ox, to leucocytes and to intestinal epithelial cells, including those of ox, to Candida albicans cells, to the mycelium of Aspergillus niger and other moulds, and to plant root-hairs. Bacilli with only the MR adhesin did not adhere to untreated red cells, leucocytes or 'smooth' yeasts, but adhered rapidly to ox and other red cells treated with tannic acid, red-cell stromata heated at $70^{\circ}$ or $100^{\circ}$, fungus mycelium and plant root-hairs. Bacilli of many fimbriate strains and one non-capsulate non-fimbriate strain adhered to glass and cellulose.

Bacterial fimbriae are filamentous appendages which are smaller and more numerous than flagella, and demonstrable only by electron microscopy (Anderson, 1949; Houwink \& van Iterson, 1950). Since Anderson interpreted fimbriae as strands of dried capsular substance, attention was given in the present study to establishing the morphological distinction between fimbriae and capsules, and the presence of fimbriae in non-capsulate mutants. Fimbriae occur widely among the Enterobacteriaceae, in a majority of strains of Escherichia coli (Duguid, Smith, Dempster \& Edmunds, 1955), Aerobacter cloacae (Constable, 1956), Shigella flexneri (Duguid \& Gillies, 1957) and Salmonella, Klebsiella, Proteus and Serratia (Duguid \& Gillies, 1958). They are thought to act as organs of attachment, since most fimbriate strains were found to have the power of adhering to animal and fungal cells, and thus of causing haemagglutination when mixed with red blood cells. Excepting Proteus, most fimbriate bacilli have shown the same kind of adhesive property, acting strongly with guinea-pig, fowl and many other species of red cells, weakly with human and sheep cells, and scarcely at all with ox cells. This 
adhesive activity is almost completely inhibited by a small concentration of D-mannose or $\alpha$-methylmannoside (Duguid \& Gillies, 1957), and the responsible agent is therefore termed the mannose-sensitive (MS) fimbrial haemagglutinin or adhesin. The alternative name 'adhesin' is introduced because the fimbriae adhere to many substrates other than red cells. A minority of fimbriate Klebsiella strains were found by Duguid \& Gillies (1958) to lack adhesive affinity for all species of red cells tested. In the present study other substrates were found for which these strains are adhesive, including mould mycelium and tannic-acid treated red cells. This adhesive activity is unaffected by mannose and the responsible agent is therefore termed the mannose-resistant (MR) fimbrial haemagglutinin or adhesin.

\section{METHODS}

Organisms. I examined 154 non-motile strains representing the Klebsiella capsule serotypes 1-72 established by Julianelle and others (see Edwards \& Fife, 1952; Edmunds, 1954; Edwards \& Ewing, 1955). Seventy strains in types 1-6 and a strain each of types 18 and 36 were obtained from the National Collection of Type Cultures, London; these are designated by the Collection number prefixed by the letter N (e.g. N. 5054). The type strains of types 7-63 and 70-72 were obtained from Dr P. R. Edwards and those of types 64-69 from Dr P. N. Edmunds; they are designated K. 7, K. 8, .., K. 72. A further type-5 and four type-38 strains (E. 5, etc.) were obtained from Dr Edwards and the remaining 11 strains (A. 1, A. 3, etc., all of type 54) were isolated in Edinburgh from faeces and other sources (Duguid, 1951; Wilkinson, Duguid \& Edmunds, 1954). The strains were maintained as stab cultures in nutrient agar. They were plated on nutrient agar and a trace of material from three typical colonies was taken as the starting inoculum for each test series of cultures.

Cultures were grown serially for $48 \mathrm{hr}$. periods at $37^{\circ}$ in $10 \mathrm{ml}$. nutrient broth in $\frac{1}{2}$ in. diameter test tubes plugged with cotton wool; they were incubated aerobically without agitation or artificial aeration. The broth contained (\% (w/v)): 1, meat extract ('Oxoid' Lab Lemco); 1, peptone ('Difco' Bactopeptone); $\mathbf{0 . 5}, \mathrm{NaCl}$; its $\mathrm{pH}$ value was $7 \cdot 3$. In many repeat experiments which gave similar results, the peptone used was 'Oxoid' Bacteriological Peptone. Surface cultures were grown on well-dried plates of nutrient agar incorporating $\mathbf{1 . 2} \%(\mathrm{w} / \mathrm{v})$ of Davis New Zealand agar in the broth. For growth measurement experiments, $20 \mathrm{ml}$. agar medium was dispensed in a 4 in. diameter Petri dish; this was inoculated uniformly over its whole surface and incubated with the lid raised about $1 \mathrm{~mm}$. to ensure free aeration and dry surface conditions. Large capsules were obtained on an excess-sugar medium (agar with $1 \%(w / v)$ glucose or lactose, $0.1 \%(\mathrm{w} / \mathrm{v})$ peptone, inorganic salts and $1 \%(\mathrm{w} / \mathrm{v})$ phosphate; adjusted to $\mathrm{pH} \mathrm{7 \cdot 3;}$ Duguid, 1948).

Measurements of growth were made on the broth cultures and on the bacilli harvested from agar plates into a volume of saline solution equal to the agar. The turbidity of a suitable dilution of the broth or suspension was measured 
with a 'Spekker' photoelectric absorptiometer and the bacilli were counted microscopically in a counting chamber.

Haemagglutination tests were made with untreated guinea-pig red cells and 'tanned' ox red cells. Guinea-pig cells from freshly drawn citrated blood were twice washed and then prepared as a $3 \%(v / v)$ suspension in saline solution $(0.85 \%, w / v, \mathrm{NaCl})$. A drop of this was mixed on a white tile with an equal drop of suspension containing about $10^{10}-10^{11}$ bacilli $/ \mathrm{ml}$., prepared by centrifuging a broth culture, decanting the supernatant liquid and mixing the deposit with the residual liquid. Mixing on the tile was continued at room temperature during $\mathbf{1 5} \mathrm{min}$. on a rocking machine which tilted to and fro 50 times/min. Coarse haemagglutination was often seen within $1 \mathrm{~min}$., but with weakly active cultures only a fine granularity appeared after 5-10 min. (Gillies \& Duguid, 1958, fig. 2).

For the test with tanned ox red cells, washed red cells were treated with $0.003 \%(\mathrm{w} / \mathrm{v})$ tannic acid for $10 \mathrm{~min}$. at $37^{\circ}$ by the method of Boyden (1951) and then twice washed before making up to a $3 \%(\mathrm{v} / \mathrm{v})$ suspension in saline. These cells showed a beginning of agglutination while in the tannic acid but, after washing, gave a suspension which was not autoagglutinable during continuous mixing for $15 \mathrm{~min}$. on the tile.

The mannose sensitivity of each reaction was observed by adding a small drop of a $2 \%(\mathrm{w} / \mathrm{v})$ D-mannose solution to the drop of red cells before adding the bacilli; the final mannose concentration (c. $0.5 \%)$ completely prevented MS haemagglutination.

The haemagglutinating power (HP) of a culture was measured by making tile tests with bacillary suspensions of different concentration and finding the weakest suspension that would give a visible reaction within $10 \mathrm{~min}$. (Duguid \& Gillies, 1957). The HP was taken as $10^{11}$ divided by the minimal agglutinating number of bacilli/ml. in the final mixture with red cells; this number was estimated from a prior turbidity measurement of the bacillary suspension, assuming that a reading of 1.0 was equivalent to $10^{\circ} \mathrm{bacilli} / \mathrm{ml}$. (it was equivalent to $0 \cdot 5-2 \cdot 0 \times 10^{9} / \mathrm{ml}$. in most cultures that were counted).

Adhesion tests. The adhesion of bacilli to red cells was observed microscopically in a wet film of part of the haemagglutination test mixture (Duguid et al. 1955). Other cells, fungus mycelium and cellulose fibres were tested by mixing them with about $10^{10}$ bacilli/ml. in a drop of saline solution $(0 \cdot 85 \%$, $\mathrm{w} / \mathrm{v}, \mathrm{NaCl}$ ) on a microscope slide. This was tilted to and fro for about $1 \mathrm{~min}$., and viewed against a dark background to detect agglutination. A coverslip was then applied and the wet film examined by the phase-contrast microscope with a $\frac{1}{12}$ in. oil-immersion objective. Yeasts and fungi for these tests were grown on nutrient or Sabouraud agar for 1 day at $30^{\circ}$ and then for a few days at $15-20^{\circ}$. Ox and human leucocytes were obtained from the buffy coat on centrifuged citrated blood, and guinea-pig leucocytes from the peritoneal cavity one day after injecting $25 \mathrm{ml}$. nutrient broth. Epithelial cells were scraped from the mucosal surface of guinea-pig and ox intestine (ileum and colon) which had been removed and washed with saline immediately after slaughter, and from human colon obtained at an operation. Red-cell stromata 
were prepared by lysing washed cells in distilled water, centrifuging and twice washing with saline. Germ-free $\frac{1}{2}-1$ in. seedlings of cress and red clover were grown on nutrient agar for 2-4 days at $c .20^{\circ}$ from seeds sterilized with ethanol and $\mathrm{HgCl}_{2}$. The seedling was immersed for $5 \mathrm{~min}$. in a saline suspension of about $10^{10}$ bacilli $/ \mathrm{ml}$., with occasional gentle shaking; it was then washed by immersion in fresh saline for $1 \mathrm{~min}$. and mounted in a wet film. Cellulose fibres were obtained as ashless, chemically prepared 'Cellulose Powder' (W. and R. Balston, Ltd.). Adhesion to glass was observed on the surface of the slide when viewing a wet film of bacilli in saline. The slides were cleaned by polishing and roasting in a flame, or by soaking in chromic-sulphuric acid solution and rinsing in distilled water.

Electron-microscopical observations of fimbriae and capsules were made on gold-palladium shadowed films of bacilli killed with $\mathbf{0 . 2 5} \%$ formaldehyde (Duguid \& Gillies, 1957). Capsules were also observed in wet films with indian ink (Duguid, 1951). Motility was tested in semi-solid agar by the method of Tittsler \& Sandholzer (1936). Biochemical reactions were tested by the methods described by Mackie \& McCartney (1956); cultures in glucose peptone medium were incubated for 5 days at $30^{\circ}$ for the methyl-red test and for 2 days at $37^{\circ}$ for the Voges-Proskauer test; citrate utilization was tested in Koser's medium at $37^{\circ}$ and at $30^{\circ}$.

\section{RESULTS}

\section{Fimbriation among 154 Klebsiella strains}

Shigella flexneri was found by Duguid \& Gillies (1957) to vary between a fimbriate and a non-fimbriate phase, the fimbriate becoming predominant after several serial aerobic cultivations in broth and the non-fimbriate after serial cultivation on nutrient agar. In view of this, each Klebsiella strain was examined in 9-10 serial cultures grown aerobically at $37^{\circ}$ for $48 \mathrm{hr}$. in tubes of nutrient broth. The first broth tube was inoculated from three colonies on agar and subsequent broth tubes with a small loopful from the surface of the preceding culture, including a fragment of any pellicle present. Haemagglutination tests were made on most of the ten cultures and electron-microscopical examinations on at least two, usually the second and sixth. A strain was accepted as fimbriate only when fimbriae were clearly demonstrated in two cultures. Many strains, including all initially found to be non-fimbriate or doubtfully fimbriate, were examined in a second series of $37^{\circ}$ broth cultures started separately from the stock culture. The strains still found non-fimbriate were examined in a series of broth cultures grown at $30^{\circ}$ and in a culture on nutrient agar.

Of the 154 strains, 125 were found to be fimbriate, including representatives of all 72 serotypes (Table 1). Five were moderately or richly fimbriate in cultures at $30^{\circ}$, but non-fimbriate or very poorly fimbriate at $37^{\circ}$; these included four type-2 strains and the type-52 strain reported as non-fimbriate by Duguid \& Gillies (1958). The fimbriate strains included all of 98 which had the biochemical reactions typical of saprophytic Klebsiella aerogenes (methyl-red negative, Voges-Proskauer positive, citrate utilizing, aerogenic in 
fermenting glucose, lactose and other sugars, and non-indole-producing). Also fimbriate were 27 strains with atypical reactions : 19 with reversed methyl-red and Voges-Proskauer reactions (mostly in types 2, 3 and 5), 3 not utilizing citrate (e.g. N. 9619), 4 anaerogenic (e.g. K. 26) and 9 producing indole (e.g. N. 8167).

The 29 strains found permanently non-fimbriate occurred exclusively in serotypes 1-6. All showed some of the atypical biochemical reactions that are common in pneumoniae, ozaenae and rhinoscleromatis strains of Klebsiella: $\mathbf{2 5}$ had reversed or doubtful methyl-red and Voges-Proskauer reactions, 9 did not utilize citrate ( 5 in types 3 and 4 ), 13 were anaerogenic in fermenting

Table 1. Fimbriae and mannose-sensitive $(M S)$ and mannose-resistant (MR) haemagglutinins (adhesins) in 154. Klebsiella strains of capsule serotypes 1-72 in broth cultures at $37^{\circ}$

$+=$ fimbriae or haemagglutinin present in most cultures of strain. $+^{30}=$ present in growths at $30^{\circ}$ and absent at $37^{\circ} .-=$ absent. $\pm=$ haemagglutinating activity never more than very weak.,$+ \pm=$ activity strong in some strains and very weak in others. $( \pm)=$ very weak activity in occasional cultures, none in most.

\begin{tabular}{|c|c|c|c|c|c|}
\hline $\begin{array}{l}\text { Sero- } \\
\text { type }\end{array}$ & $\begin{array}{l}\text { No. of } \\
\text { strains }\end{array}$ & Example strains & Fimbriae & $\begin{array}{l}\text { MS, } \\
\text { guinea-pig } \\
\text { cells }\end{array}$ & $\begin{array}{l}\text { MR, } \\
\text { tanned ox } \\
\text { cells }\end{array}$ \\
\hline 1 & $\begin{array}{l}8 \\
4\end{array}$ & $\begin{array}{l}\text { N. } 5054, \text { N. } 9618 \\
\text { N. } 9494, \text { N. } 9499\end{array}$ & $\bar{t}$ & $\bar{t}$ & $\bar{t}$ \\
\hline $\mathbf{2}$ & $\begin{array}{r}2 \\
12 \\
4\end{array}$ & $\begin{array}{l}\text { N. } 7242, \text { N. } 7761 \\
\text { N. } 9503, \text { N. } 9621 \\
\text { N. } 5055, \text { N. } 9620\end{array}$ & $\begin{array}{l}- \\
+ \\
+30\end{array}$ & $\begin{array}{c}- \\
+, \pm \\
-, \pm \pm^{30}\end{array}$ & $\begin{array}{c}\overline{+} \\
\pm,+{ }^{30}\end{array}$ \\
\hline 3 & $\begin{array}{l}3 \\
8\end{array}$ & $\begin{array}{l}\text { N. 5046, N. } 5047 \\
\text { N. 5056, N. } 9633\end{array}$ & $\overline{+}$ & $+\bar{t} \pm$ & $\overline{-}$ \\
\hline 4 & $\begin{array}{l}9 \\
1 \\
1 \\
2\end{array}$ & $\begin{array}{l}\text { N. } 5050, \text { N. } 9626 \\
\text { N. } 9644 \\
\text { N. } 9646 \\
\text { N. } 9652 \text {, N. } 9656\end{array}$ & $\begin{array}{l}- \\
+ \\
+ \\
+\end{array}$ & $\begin{array}{l}- \\
+ \\
\pm \\
-\end{array}$ & $\begin{array}{l}- \\
\bar{t} \\
+\end{array}$ \\
\hline $\mathbf{5}$ & $\begin{array}{l}5 \\
2 \\
1\end{array}$ & $\begin{array}{l}\text { N. } 5051, \text { N. } 9664 \\
\text { N. } 9660, \text { N. } 9663 \\
\text { E. } 5\end{array}$ & $\begin{array}{l}- \\
+ \\
+\end{array}$ & $\dot{+}$ & $\begin{array}{l}\overline{+} \\
+\end{array}$ \\
\hline 6 & $\begin{array}{l}2 \\
7\end{array}$ & $\begin{array}{l}\text { N. } 5052, \text { N. } 9666 \\
\text { N. } 9668, \text { N. } 9670\end{array}$ & $\bar{t}$ & $+\bar{t} \pm$ & $\bar{t}$ \\
\hline 18 & $\begin{array}{l}1 \\
1\end{array}$ & $\begin{array}{l}\text { K. } 18 \\
\text { N. } 8167\end{array}$ & + & \pm & + \\
\hline 36 & $\begin{array}{l}1 \\
1\end{array}$ & $\begin{array}{l}\text { K. } 36 \\
\text { N. } 5939\end{array}$ & $\begin{array}{l}+ \\
+\end{array}$ & \pm & $\begin{array}{l}+ \\
+\end{array}$ \\
\hline 38 & $\begin{array}{l}1 \\
\mathbf{2} \\
\mathbf{2}\end{array}$ & $\begin{array}{l}\text { K. } 38 \\
\text { E. } 4324, \text { E. } 4683 \\
\text { E. 2802, E. } 5070\end{array}$ & $\begin{array}{l}+ \\
+ \\
+\end{array}$ & $\bar{t}+$ & $\begin{array}{l}( \pm)^{30} \\
+ \\
( \pm)\end{array}$ \\
\hline $\mathbf{5 4}$ & 12 & K. 54, A. 3 & + & + & + \\
\hline \multicolumn{6}{|c|}{ type-strain only was examined in each of the following types: } \\
\hline \multicolumn{3}{|c|}{$\begin{array}{l}40,55 \\
8,10-17,19-25,27,28,30,32-35,37,39 \text {, } \\
41-51,53,56-64,72\end{array}$} & $\begin{array}{l}+ \\
+\end{array}$ & $\begin{array}{c}+ \\
+, \pm\end{array}$ & $\bar{t}$ \\
\hline \multicolumn{3}{|c|}{$31,65,71$} & $\begin{array}{l}+ \\
+ \\
+30\end{array}$ & $\begin{array}{l}+30 \\
- \\
-\end{array}$ & $\begin{array}{l}+ \\
+ \\
+30\end{array}$ \\
\hline
\end{tabular}


glucose, 4 did not ferment lactose (e.g. N. 5046) and others gave delayed fermentation of lactose. None of the 154 klebsiellas was motile in semi-solid agar and none showed flagella by the electron microscope.

\section{Morphology of fimbriae and capsules}

Except where obscured by large capsules or a deposit of slime, the fimbriae of Klebsiella strains with MS adhesin showed the same morphology as the fimbriae of Escherichia coli and Shigella flexneri (Pl. 1, fig. 1; Pl. 2, fig. 4; Pl. 3, fig. 7). They were similar in length, width $(c .0 .01 \mu)$, absence of flagellartype wave form, peritrichous distribution and number/bacillus (often 100-300, but sometimes under 50). In strains having only the MR type of adhesive activity, the fimbriae appeared to be thinner (perhaps about $0.007 \mu$ ) and more pliable (Pl. 3, fig. 5). Since the apparent width of the fimbriae varied to some extent with uncontrolled minor differences in specimen-preparation and microscopy, the distinction between the two kinds of fimbriae could not be established beyond doubt. It was most convincingly apparent in cultures having both the MS and MR adhesins, where the same microscope field showed some bacilli with the thick fimbriae and others with the thin; the two kinds were not seen together on the same bacillus.

On examination of broth cultures by the wet-film indian ink method, 151 of the 154 strains were found to be capsulated, though some showed visible capsules on only a proportion of cells (e.g. N. 9494). Strains N. 9655, N. 9663 and N. 9666 appeared to be non-capsulate. In broth and on nutrient agar most strains formed small capsules, e.g. $0 \cdot 2-0 \cdot 5 \mu$ in radial thickness and $1 \cdot 2-2 \cdot 0 \mu$ in transverse diameter; a few formed much larger capsules, mainly 2-4 $\mu$ in transverse diameter (e.g. all the non-fimbriate type-1 strains and the fimbriate type-4 strain N. 9644).

The capsules were less clearly demonstrable by the electron microscope due to their low solid content and great shrinkage on drying. They usually appeared as a narrow, indefinite zone of faint opacity and were recognized mainly because they obscured the sharp margins of the cell-wall fold which surrounds the shrunken bacillary protoplast (cf. Pl. 2, figs. 2 and 3). In fimbriate bacilli, they usually obscured the fimbriae for only a very short distance at their proximal ends ( $\mathrm{Pl}$. 1, fig. 1). In bacilli with very large capsules grown on excess-sugar medium, the fimbriae could be seen passing through the capsule and then outwards beyond it ( $\mathrm{Pl}$. 3, fig. 6). In some parts of most films, the fimbriae were matted together and grossly obscured by the capsular substance and slime.

Non-capsulate non-slime-forming $(\mathbf{O})$ mutants were isolated from the broth cultures of 16 capsulate fimbriate strains, including N. 9499, K. 9, K. 55 and A. 3. These mutants gave non-mucoid growths on nutrient agar and excesssugar medium, showing no trace of capsules or slime in indian ink films. The A. 3(0) mutant was proved by serological tests to lack the specific type-54 exopolysaccharide of its parent strain (Wilkinson et al. 1954, Table 2). All these non-capsulate mutants were found to be normally fimbriate. Their fimbriae and cell walls were seen unobscured by capsular material (Pl. 2, fig. 4). 


\section{Haemagglutinating and adhesive properties}

All 154 strains were tested for haemagglutination of untreated guinea-pig red cells and tanned ox red cells, and for the susceptibility of their reactions to inhibition by mannose; tile tests were made with the centrifuged bacillary deposits of the serial broth cultures and the results are shown in Table 1. All strains were further examined in saline wet films for adhesion to the mycelium of Aspergillus niger and the surface of the glass slide. The 'strength' of the adhesive activity of a culture was judged from the number of bacilli which adhered to the substrate within a few minutes. Firm adhesion of the bacilli was assumed from their lack of Brownian movement and their failure to move from the site of adherence when disturbed by quick small movements of the fine-focusing adjustment. Reactions with other substrates were tested on a selection of 15-30 representative strains, including N. 5054, N. 7242, N. 7242(0), N. 9499, N. 9644, N. 9652, K. 9, K. 40, K. 55, E. 5, A. 3 and A. 3(0).

\section{Table 2. Adhesive affinity for various substrates of fimbriate strains with $M S$ and $M R$ adhesins and of non-fimbriate strains}

Results in first three columns are for richly fimbriate cultures only; those in third are for cultures with MS and MR adhesins in about equal strength. $-=$ no adhesion, $\pm=$ very few bacilli adhering, + to $+++=$ increasing numbers of bacilli adhering within 5 min. period. Alternative results, e.g.,-+++ , are extremes for different cultures and strains. Rare results are shown thus ( + ) etc. The mannose-sensitivity of the reaction is shown as $\mathrm{S}=$ sensitive, $\mathbf{R}=$ resistant, $\mathbf{S R}=$ slightly sensitive.

\begin{tabular}{|c|c|c|c|}
\hline $\begin{array}{l}\text { Strains } \\
\text { with MS } \\
\text { adhesin } \\
\text { only }\end{array}$ & $\begin{array}{l}\text { Strains } \\
\text { with MR } \\
\text { adhesin } \\
\text { only }\end{array}$ & $\begin{array}{c}\text { Strains } \\
\text { with } \\
\text { MS and MR } \\
\text { adhesins }\end{array}$ & $\begin{array}{l}\text { Non- } \\
\text { fimbriate } \\
\text { strains }\end{array}$ \\
\hline $\begin{array}{l}+++\mathbf{S} \\
+++\mathbf{S} \\
+++\mathbf{S} \\
+++\mathbf{S} \\
+++\mathbf{S} \\
+++\mathbf{S}\end{array}$ & $\begin{array}{r}\overline{ \pm} \\
\pm \mathbf{R} \\
++\mathbf{R} \\
+++\mathbf{R} \\
-\bar{R}\end{array}$ & $\begin{array}{l}+++\mathbf{S} \\
+++\mathbf{S} \\
+++\mathbf{R} \\
+++\mathbf{R} \\
+++\mathbf{S} \\
+++\mathbf{S R}\end{array}$ & $\begin{array}{c}- \\
-\overline{( \pm)} \\
-,( \pm) \\
- \\
-\end{array}$ \\
\hline $\begin{array}{r}- \\
\pm S \\
+S \\
+S \\
+++S \\
+++S\end{array}$ & $\begin{array}{c}- \\
- \\
++\mathbf{R} \\
+++\mathbf{R} \\
- \\
+\mathbf{R}\end{array}$ & $\begin{array}{r}-\overline{\mathbf{S}} \\
++\mathbf{R} \\
+++\mathbf{R} \\
+++\mathbf{S} \\
+++\mathbf{S R}\end{array}$ & $\begin{array}{c}- \\
- \\
-,( \pm) \\
-,( \pm) \\
- \\
-\end{array}$ \\
\hline $\begin{array}{l}+++\mathbf{S} \\
+++\mathbf{S} \\
+++\mathbf{S} \\
+++\mathbf{S} \\
+++\mathbf{S}\end{array}$ & $\begin{array}{r}\overline{+} \mathbf{R} \\
+\mathbf{R} \\
+++\mathbf{R} \\
+++\mathbf{R}\end{array}$ & $\begin{array}{l}+++\mathbf{S} \\
+++\mathbf{R} \\
+++\mathbf{R} \\
+++\mathbf{R} \\
+++\mathbf{R}\end{array}$ & $\begin{array}{c}- \\
- \\
- \\
-,( \pm) \\
-,( \pm)\end{array}$ \\
\hline $\begin{array}{l}-,++\mathbf{R} \\
-,+++\mathbf{R}\end{array}$ & $\begin{array}{l}+++,(+) \mathbf{R} \\
+++,(+) \mathbf{R}\end{array}$ & $\begin{array}{l}+++,(+) \mathbf{R} \\
+++,(+) \mathbf{R}\end{array}$ & $\begin{array}{l}-,(++) \mathbf{R} \\
-,(++) \mathbf{R}\end{array}$ \\
\hline
\end{tabular}

Guinea-pig red cells

Guinea-pig red-cell stromata

Heated guinea-pig red-cell stromata

Tanned guinea-pig red-cells

Guinea-pig leucocytes

Guinea-pig intestinal epithelium

Ox red cells

Ox red-cell stromata

Heated ox red-cell stromata

Tanned ox red cells

Ox leucocytes

Ox intestinal epithelium

'Smooth' Candida albicans

Heated 'smooth' C. albicans

'Rough' C. albicans

Aspergillus niger mycelium

Cress plant root hairs

Glass slide

Cellulose fibres

The 154, strains were divisible into four groups having the adhesive properties shown in the four columns of Table 2. There were: 11 fimbriate strains with MS activity only; 18 fimbriate strains with MR activity only; 96 fimbriate strains with MS and MR activities together; 29 non-fimbriate strains virtually 
devoid of adhesive activity. Only the 107 strains which had MS adhesin were able to agglutinate untreated guinea-pig red cells, while only the 114 strains which had MR adhesin were able to agglutinate tanned ox red cells in $0.5 \%$ (w/v) D-mannose. Both the MS and MR adhesins were active for Aspergillus niger mycelium and certain other substrates; cultures which had both adhesins gave mannose-resistant reactions with these substrates.

The stability of the fimbriae was similar to that found in Shigella flexneri by Gillies \& Duguid (1958). The MS and MR haemagglutinating properties were destroyed by heating the bacilli at $90^{\circ}$ for $30 \mathrm{~min}$., but were usually little affected by heating at $60^{\circ}$ for $30 \mathrm{~min}$. or by exposure to $2 \%$ formaldehyde at $37^{\circ}$ for $3 \mathrm{hr}$. The MR activity of a few strains (e.g. K.9) was markedly decreased by the latter procedures. No evidence was obtained for the existence of a soluble haemagglutinin; neither MS nor MR activity could be demonstrated in bacteria-free supernatant fluids from centrifuged broth cultures.

\section{Properties of the MS fimbrial adhesin}

The red cells found most susceptible to MS agglutination were those of the guinea-pig. The haemagglutinating power (HP) of a culture for these red cells differed with the strain and degree of fimbriation (Table 3). The most strongly active (e.g. of K. 55) had an HP value of 1000-3000, giving a just visible reaction in mixtures of about 1 bacillus/2-6 red cells. The weakest (e.g. of N. 9633) had an HP value of less than 5, requiring over 100 bacilli/red cell to give a visible reaction. Highly active cultures also agglutinated fowl, toad and horse red cells fairly strongly, rabbit and human cells weakly, sheep cells very weakly and ox cells not at all (some $K$. 55 cultures gave a trace reaction with ox cells).

Haemagglutination was caused by a rapid firm adhesion of bacilli to the red cells. This was seen microscopically in wet films as described by Duguid et al. (1955). Fimbriate bacilli with large capsules (e.g. N. 9644) appeared fixed to the red-cell surface with an intervening gap of up to $2 \mu$; addition of indian ink showed that this gap was occupied by capsule. The presence of $0.5 \% \mathrm{D}$-mannose in all cases inhibited the agglutination of untreated red cells. Usually inhibition was complete, but in some cultures (especially at $30^{\circ}$ ) of a few strains (e.g. of type 3 ) it was only partial. In the latter case, microscopical examination showed that the adhesion of bacilli had been prevented by the mannose and that the red cells were weakly agglutinated by a fine crystalline debris apparently derived from the culture. Haemagglutination was inhibited by $0.5 \% \alpha$-methylmannoside as effectively as by mannose, but was unaffected by $0.5 \%$ or $2.5 \%$ of D-glucose, $\alpha$-methylglucoside, D-lyxose, D-galactose, D-xylose, D-raffinose, L-arabinose, L-rhamnose, maltose, lactose, sucrose, glycerol, mannitol or sorbitol.

Strains with $M S$ adhesin but no $M R$ adhesin. These adhered to and agglutinated the washed stromata of lysed guinea-pig red cells, and also stromata which had been heated at $70^{\circ}$ or $100^{\circ}$ for 5 min. They agglutinated red cells treated with $0.003 \%(\mathrm{w} / \mathrm{v})$ tannic acid solution even more strongly than untreated cells, and thus often gave a definite though weak reaction with 
tanned ox cells. They rapidly adhered to and agglutinated guinea-pig, human and ox leucocytes (Pl. 4, fig. 8); on mixture with the buffy coat of ox blood they agglutinated the leucocytes and platelets, leaving the red cells unaffected. The MS strains showed rapid adhesion to fresh epithelial cells scraped from the mucosa of guinea-pig ileum and colon, human colon and ox ileum and colon, as described for Shigella flexneri by Duguid \& Gillies (1957). They also adhered to and strongly agglutinated the yeast-like cells of Candida albicans, from two smooth-colony strains and from a rough-colony strain whose cells tended to remain attached in groups. The MS strains adhered strongly to the mycelium

Table 3. Mannose-sensitive (MS) and mannose-resistant (MR) haemagglutinating powers of serial $48 \mathrm{hr}$. aerobic cultures at $37^{\circ}$ on agar plates and in tubes of broth

Haemagglutinating power (see methods), $-=$ nil, $\pm=2-8,+=9-36,++=40-160,+++=180-750$, $++++=800-3000$. MS power tested with guinea-pig cells and MR with tanned ox cells. The 'Agar' and 'Broth' series were started from the same 8-colony inoculum, and the 'Broth'' series from a different agar inoculum. The first plate of the 'Agar B' series was inoculated from the 9th broth culture of the series shown immediately above it.

\begin{tabular}{|c|c|c|c|c|c|c|c|c|c|}
\hline \multirow[b]{2}{*}{ Strain } & \multirow[b]{2}{*}{ Medium } & \multicolumn{2}{|c|}{$\begin{array}{c}\text { Ist } \\
\text { culture }\end{array}$} & \multicolumn{2}{|c|}{$\begin{array}{c}\text { 3rd } \\
\text { culture }\end{array}$} & \multicolumn{2}{|c|}{$\begin{array}{c}\text { 5th } \\
\text { culture }\end{array}$} & \multicolumn{2}{|c|}{$\begin{array}{c}\text { 9th } \\
\text { culture }\end{array}$} \\
\hline & & MS & MR & MS & MR & MS & MR & MS & MR \\
\hline N. 9633 & $\begin{array}{l}\text { Agar } \\
\text { Broth }\end{array}$ & \pm & - & \pm & - & $\begin{array}{l} \pm \\
\pm\end{array}$ & $\overline{-}$ & \pm & - \\
\hline K. 55 & $\begin{array}{l}\text { Agar } \\
\text { Broth } \\
\text { Agar B }\end{array}$ & $\begin{array}{r}+ \\
++++ \\
+++\end{array}$ & - & $+++\frac{ \pm}{ \pm}$ & $\overline{-}$ & $\begin{array}{r}+ \\
+ \\
\pm\end{array}$ & $\bar{z}$ & $\begin{array}{r} \pm \\
+ \\
+\end{array}$ & - \\
\hline N. 9499 & $\begin{array}{l}\text { Agar } \\
\text { Broth } \\
\text { Agar B }\end{array}$ & $\begin{array}{r}++ \\
++ \\
+++\end{array}$ & $\begin{array}{r} \pm \\
+ \\
++\end{array}$ & $\begin{array}{r}+ \\
++ \\
+\end{array}$ & $\begin{array}{r}-\overline{+} \\
\pm\end{array}$ & $\begin{array}{r}+ \\
++ \\
+\end{array}$ & $+\stackrel{ \pm}{+}$ & $\begin{array}{r}++ \\
+++ \\
+\end{array}$ & $\begin{array}{r}- \\
++ \\
\pm\end{array}$ \\
\hline A. 3 & $\begin{array}{l}\text { Agar } \\
\text { Broth } \\
\text { Agar B } \\
\text { Broth } \\
\text { Agar B }^{2}\end{array}$ & $\begin{array}{r} \pm \\
\pm \\
++ \\
++ \\
++\end{array}$ & $\begin{array}{r}- \\
+ \\
+ \\
+ \\
++\end{array}$ & $\begin{array}{r} \pm \\
++ \\
+ \\
++ \\
++\end{array}$ & $\begin{array}{r}\overline{-} \\
\pm \\
++ \\
+++\end{array}$ & $\begin{array}{r}+ \\
++ \\
+ \\
++ \\
++\end{array}$ & $\begin{array}{r} \pm \\
\pm \\
\pm \\
++++ \\
+++\end{array}$ & $\begin{array}{r} \pm \\
++ \\
\pm \\
+t \\
+++\end{array}$ & $\begin{array}{r} \pm \\
\pm \\
+t \\
+++ \\
+++t\end{array}$ \\
\hline K. 13 & $\begin{array}{l}\text { Agar } \\
\text { Broth }\end{array}$ & $+++\stackrel{ \pm}{+}$ & $\begin{array}{l}+++ \\
+++\end{array}$ & + \pm & $\begin{array}{r}+++ \\
+++\end{array}$ & $+\stackrel{+}{+}$ & $\begin{array}{r}+++ \\
+++\end{array}$ & $+++\stackrel{ \pm}{+}$ & $\begin{array}{l}+++ \\
+++\end{array}$ \\
\hline N. 9503 & $\begin{array}{l}\text { Agar } \\
\text { Broth }\end{array}$ & \pm & $\begin{array}{r}+++ \\
++++\end{array}$ & \pm & $\begin{array}{l}+++ \\
+++\end{array}$ & \pm & $\begin{array}{r}+++ \\
+++\end{array}$ & \pm & $\begin{array}{r}+++ \\
+++\end{array}$ \\
\hline K. $\theta$ & $\begin{array}{l}\text { Agar } \\
\text { Broth }\end{array}$ & $\begin{array}{l}- \\
-\end{array}$ & $\begin{array}{l}++++ \\
++++\end{array}$ & - & $\begin{array}{l}++++ \\
++++\end{array}$ & $\overline{-}$ & $\begin{array}{l}++++ \\
++++\end{array}$ & - & $\begin{array}{l}++++ \\
++++\end{array}$ \\
\hline
\end{tabular}

and conidia of various saprophytic and parasitic fungi, namely Aspergillus niger, Penicillium sp., Rhizopus sp., Epicoccum sp., Fusarium nivale, Thamnidium elegans, Trichoderma viride, Phoma foveata, Helminthosporium avenae, Botrytis cinerea, Monosporium apiospermum, Trichophyton sulphureum and Microsporum gypseum (see similar adhesion by MR strain, Pl. 4, fig. 10). These MS strains also adhered to the root hairs of cress and red clover seedlings (see similar adhesion by an MS and MR strain, Pl. 4, fig. 9). All these adhesive activities were largely inhibited by the presence of $0.5 \%$ mannose.

Some cultures of strains K. 40 and K. 55 showed adhesive affinity for glass 
and cellulose. When mounted in a saline wet film, up to $30 \%$ or more of the bacilli might become firmly attached to the surfaces of the slide and coverslip within 2-3 min., and many to cellulose fibres when these were included. This adhesive property seemed to be unrelated to the MS adhesin, since it was unaffected by mannose and was not present in many richly fimbriate cultures with strong MS activity (e.g. N. 9644). Tests made in distilled water showed that electrolyte (e.g. $\mathbf{0 . 8 5} \% \mathrm{NaCl}$ ) was required for adhesion to glass and for MS adhesion to Aspergillus niger. Mycelium and bacilli (K. 40 or K. 55) were killed by $0.5 \%$ formaldehyde and washed in several changes of distilled water before mounting together between a washed slide and coverslip. Very few bacilli adhered to the mycelium or slide during 5 min. in distilled water, but many began to adhere soon after the addition of a little salt to the edge of the film.

Non-haemolytic fimbriate strains of Escherichia coli, Aerobacter cloacae, Shigella flexneri and Salmonella have the same adhesive properties as the Klebsiella strains with MS adhesin only (Table 2, first column). Their reactions with substrates not previously tested by Duguid et al. (1955), Constable (1956) and Duguid \& Gillies $(1957,1958)$ were demonstrated in the present study for a few representative strains of each species. Ten strains of Serratia marcescens acted as Klebsiella strains possessing MS and MR adhesins, or MR adhesin only.

\section{Properties of the $M R$ fimbrial adhesin}

The 18 strains having only the MR adhesin neither adhered to nor agglutinated any of the following preparations : fresh red cells of the guinea-pig, fowl, toad, horse, mouse, rabbit, man, sheep and ox; unheated guinea-pig and ox red-cell stromata; guinea-pig, human and ox leucocytes; unheated 'smooth' Candida albicans. They did not cause haemagglutination even in tests made at 3-5 ${ }^{\circ}$ (cf. haemolytic Escherichia coli strains, Duguid et al. 1955), and showed only a scanty adhesion of bacilli to intestinal epithelial cells.

On the other hand, the MR strains rapidly adhered to and strongly agglutinated red-cell stromata which had been heated in saline at $70^{\circ}$ or $100^{\circ}$ for $5 \mathrm{~min}$., and intact red cells which had been treated with $0.003 \%(\mathrm{w} / \mathrm{v})$ tannic acid solution, irrespective of whether these had originated from ox, man, guinea-pig or other animal. Tanned ox cells were chosen for the standard test of MR activity, since they gave the most stable suspensions and were the least susceptible to MS adhesin.

All the MR strains showed strong adhesion to the mycelium and conidia of Aspergillus niger and other moulds (Pl. 4, fig. 10). Such strains also adhered strongly to the root hairs of cress and red clover seedlings (cf. MS and MR strain, Pl. 4, fig. 9). They adhered, usually weakly, to 'smooth' Candida albicans that had been heated in saline at $100^{\circ}$ for $5 \mathrm{~min}$. and to unheated cells of the 'rough' $C$. albicans strain. In saline wet films they adhered to the glass slide and coverslip, and to cellulose fibres; in most cultures this tendency was very strong and up to $50 \%$ or more of the bacilli might become attached within 1-2 min. Many MR cultures were autoagglutinable. All these adhesive 
activities were resistant to inhibition by mannose. They were partly dependent on the presence of electrolyte, since adhesion to fungus mycelium and glass was less when the tests were made in distilled water instead of saline.

\section{Properties of non-fimbriate strains}

All 29 non-fimbriate strains were found to lack adhesive affinity for guinea-pig red cells, tanned ox red cells, Candida albicans, Aspergillus niger mycelium and glass. At most, a rare bacillus was found adherent at a few places on the tanned cells, mould mycelium or glass. Representative strains of each serotype lacked adhesive affinity for fowl, toad, horse, mouse, rabbit, human, sheep and ox red cells, heated red-cell stromata, guinea-pig, human and ox leucocytes, intestinal epithelial cells, plant root hairs and cellulose fibres (Table 2). Exceptional results were obtained with a non-capsulate mutant derived from the non-fimbriate strain N. 7242. Its cultures were partly autoagglutinable in saline and showed a moderate adhesiveness for glass and cellulose. These properties were dependent on the presence of electrolyte. They were also found in some non-fimbriate strains of other species (e.g. Escherichia coli strain 55 of Duguid et al. 1955).

Weak mannose-resistant haemagglutination reactions were given by the concentrated bacillary deposits from a few cultures of non-fimbriate strains, especially those grown at $30^{\circ}$; microscopical examination revealed that these reactions occurred without adhesion of bacilli to red cells. The clumped red cells appeared interspersed with and bound together by a fine particulate debris and some bundles of long tyrosine-like crystals, presumably products of bacterial growth. When using the haemagglutination test to detect fimbriation in klebsiellas, it is thus necessary, when a weak reaction is obtained, to demonstrate microscopically that it involves bacillary adhesion. Weak non-bacillary agglutination occurred similarly with tanned red cells, red-cell stromata and Candida albicans.

\section{Variation in fimbriation and haemagglutinating activity}

The broth cultures of all fimbriate strains were found to contain a proportion of non-fimbriate as well as fimbriate bacilli. In most strains 50-90\% of the bacilli were fimbriate and in a few (e.g. of type 3) never more than 5-25\%. This was probably the result of frequent reversible variation between a fimbriate phase and a non-fimbriate phase, as found in Escherichia coli by Brinton, Buzzell \& Lauffer (1954) and Shigella flexneri by Duguid \& Gillies (1957). Cultures of a few strains (e.g. K. 9) never showed more than $c .10 \%$ of non-fimbriate bacilli, and the possibility must be admitted that these were originally fimbriate, but had lost their fimbriae after dying in the culture or during preparation of the specimen.

The combined MS and MR haemagglutinating powers seemed to vary directly with the proportion of fimbriate bacilli in the culture. Observations were made on 35 strains carried in parallel through nine serial $48 \mathrm{hr}$. cultures on nutrient agar plates and nine serial $48 \mathrm{hr}$. cultures in broth, both series being started from the same 3-colony inoculum (e.g. 'Agar' and 'Broth' series, Table 3). For some strains a second series of nutrient agar cultures ('Agar B') 
was started with an inoculum from the richly-fimbriate 9 th culture of the broth series. Maximal fimbriation was found to develop during the cultivation in broth. The serial cultivation on nutrient agar did not decrease the proportion of fimbriate bacilli in a few strains (e.g. K. 9), but decreased it to between $10 \%$ and $50 \%$ in most, and to as little as $1 \%$ in some (e.g. K. 55). In no case, however, did it yield a culture entirely in the non-fimbriate phase, as in Shigella flexneri and a few Escherichia coli strains (e.g. nos. 93, 108 and 208, Duguid et al. 1955). The klebsiellas behaved instead like the majority of $E$. coli strains.

When a poorly fimbriate nutrient agar culture was subcultivated in broth, it usually achieved moderate or maximal fimbriation in the first $48 \mathrm{hr}$. broth culture, though in some cases not until the second or third (e.g. A. 3, 'Broth' series, Table 3). When a richly fimbriate broth culture of a variable strain was subcultivated on nutrient agar, the first $48 \mathrm{hr}$. culture was moderately fimbriate and the second or third minimally fimbriate (e.g. K. 55 and N. 9499, 'Agar B' series, Table 3). Because conversion between the fimbriate and nonfimbriate phases was so rapid, the experiments did not show whether the change was directly impressed by the cultural conditions or was due to selection of mutants. 'The latter mechanism appears the more likely, since some evidence was obtained for its operation in Shigella flexneri (Duguid \& Gillies, 1957). Fimbriate bacilli fixed while undergoing fission were mostly fully fimbriate at both ends. Rarely, however, one daughter cell was fimbriate and the other non-fimbriate (Pl. 3, fig. 7); this might be the result of fimbrial phase variation.

In strains capable of both MS and MR haemagglutination, these two activities could vary independently in strength and one might even disappear from a culture while the other remained. Serial cultivation in broth often brought about a large relative increase of MR activity, e.g. in 4 out of 6 experiments with strain A. 3 (cf. 'Broth'' and 'Broth' series, Table 3). When the MR-rich A. 3 broth cultures were subcultivated on nutrient agar, they gave mucoid (capsulate) colonies which differed from the parent type in being more convex and opaque. This variant continued to yield fully fimbriate growths with strong $\mathrm{MR}$ activity through 15 serial cultures on nutrient agar ('Agar B'' series, A. 3, Table 3), while the MS-rich parent form became mainly non-fimbriate ('Agar B' series). In other cases, fimbriation and MR activity were greatly diminished when an MR-rich broth culture was subcultivated on nutrient agar ('Agar B' series, N. 9499, Table 3). Non-capsulate (O) mutants of strains N. 9499 and A. 3 behaved in the same ways as their parent strains, but showed less tendency to produce the MR-rich variant.

\section{Pellicle formation and amount of growth}

Duguid \& Gillies (1957) found that Shigella flexneri in its non-fimbriate phase did not form a surface pellicle when grown in broth, while the fimbriatephase bacilli formed a thin membranous pellicle and gave a much greater amount of organism because of the free aeration of the bacilli in the pellicle. In Klebsiella, fimbriation appeared similarly to assist pellicle formation and 
thus augment growth, but complicating factors make the relationship difficult to prove. A surface pellicle was formed by most fimbriate Klebsiella strains in aerobic static broth cultures. In some cases it was thin and transparent like that of Shigella flexneri, but usually it was thickened by a white granular, creamy or waxy growth, or by mucoid material. Few of the non-fimbriate strains formed a complete pellicle (as N. 7242 and N. 7761), but most of them formed a 'rim' or ring of solid growth which adhered to the walls of the tube at the broth surface. This rim was usually 1-4 mm. deep and extended inwards over the broth for a similar distance. In the same way as a pellicle, the rim procured highly aerobic conditions for growth. A few non-fimbriate strains in types 4,5 and 6 (e.g. N. 9657, N. 9659, N. 9666) usually did not form a rim. Fimbriate strains formed a narrow rim in addition to their pellicle. Neither rim nor pellicle was formed in broth cultures incubated anaerobically.

Table 4. Mean of turbidity measurements of amount of growth of fimbriate and non-fimbriate strains in broth and on nutrient agar after $48 \mathrm{hr}$. at $37^{\circ}$

\begin{tabular}{|c|c|c|c|c|}
\hline Serotype & $\begin{array}{l}\text { No. of } \\
\text { strains }\end{array}$ & $\begin{array}{c}\text { Anaerobic } \\
\text { tube of } \\
\text { broth }\end{array}$ & $\begin{array}{c}\text { 'Aerobic' } \\
\text { tube of } \\
\text { broth }\end{array}$ & $\begin{array}{c}\text { Aerobic } \\
\text { agar } \\
\text { plate }\end{array}$ \\
\hline \multicolumn{5}{|c|}{ Non-fimbriate; no rim or pellicle on aerobic broth } \\
\hline $4,5,6$ & 7 & $0 \cdot 17$ & $\mathbf{0 . 2 8}$ & $\mathbf{2 \cdot 3 8}$ \\
\hline \multicolumn{5}{|c|}{ Non-fimbriate; rim but no pellicle on aerobic broth } \\
\hline $\mathbf{1}$ & 6 & $0 \cdot 17$ & $0 \cdot 89$ & $2 \cdot 45$ \\
\hline $4,5,6$ & 11 & $0 \cdot 16$ & 0.58 & $\mathbf{3} \cdot \mathbf{0 3}$ \\
\hline \multicolumn{5}{|c|}{ Non-fimbriate; rim and pellicle on aerobic broth } \\
\hline 1 & $\mathbf{2}$ & $0 \cdot 16$ & $1 \cdot 10$ & $\mathbf{2 . 5 8}$ \\
\hline 2 & 2 & $\mathbf{0} \cdot \mathbf{2 5}$ & $\mathbf{1 \cdot 2 7}$ & $3 \cdot 42$ \\
\hline \multicolumn{5}{|c|}{ Fimbriate; rim and pellicle on aerobic broth } \\
\hline 1 & 4 & $\mathbf{0} \cdot \mathbf{2 9}$ & $1 \cdot 67$ & $3 \cdot 46$ \\
\hline 2 & 11 & $0 \cdot 30$ & 1.78 & 3.97 \\
\hline $4,5,6$ & 15 & 0.29 & 1.44 & $3 \cdot 67$ \\
\hline
\end{tabular}

The influence of rim and pellicle formation on the amount of growth was investigated for most strains in types $1,2,4,5$ and 6 . Turbidity measurements were made on three cultures of each strain: (1) in a tube of broth incubated anaerobically in hydrogen; (2) in a tube of broth incubated aerobically; (3) on the growth from the whole surface of a nutrient agar plate incubated aerobically. The three cultures were inoculated from the same aerobic $48 \mathrm{hr}$. broth culture (itself inoculated from nutrient agar) and were incubated at $37^{\circ}$ for $48 \mathrm{hr}$., by which time growth was largely complete. The averages of the $48 \mathrm{hr}$. growth measurements in different groups of strains are shown in Table 4. The non-fimbriate strains which formed neither rim nor pellicle gave in the 'aerobic' broth (whose depths remained nearly anaerobic) a growth which was little more than that in the anaerobic broth (e.g. 1.5-fold) and scarcely an eighth of that on the aerobic plate. They thus behaved in the same way as nonfimbriate Shigella flexneri (Duguid \& Gillies, 1957, Table 3). The non-fimbriate strains which formed a rim gave relatively much greater growth in 'aerobic' broth (e.g. 4 times that in anaerobic broth). The fimbriate and non-fimbriate 
strains which formed a pellicle gave even more (e.g. 5 times that in anaerobic broth and nearly half that on aerobic agar). The increased growth was probably due to the abundant oxygen supply enjoyed by the bacilli which composed the rim and pellicle. In cultures on agar and in anaerobic broth, where no advantage could be gained by pellicle formation, the fimbriate strains still gave greater growth than the non-fimbriate, but the difference was very much less than with the 'aerobic' broth.

\section{DISCUSSION}

Capsulated Klebsiella strains are found to be fimbriate except for a minority which correspond to pathogenic pneumoniae, ozaenae and rhinoscleromatis varieties. That the fimbriae and capsules are independent structures is proved by their morphological differences and the occurrence of fimbriae in noncapsulated mutants. The functions of fimbriae and capsules appear to be complementary. The highly hydrophilic, negatively charged capsule has a repellent and dispersive action, helping to prevent autoagglutination of the bacilli and their adhesion to external solids, and perhaps helping to repel phagocytes, protozoal predators and bacteriophage (Wilkinson, 1958). The fimbriae, on the other hand, confer adhesive properties on the bacilli; they pass out beyond the capsule and can fasten firmly to a variety of solid substrates. Most fimbriate Klebsiella strains seem capable of reversible variation between a fimbriate and a non-fimbriate phase. This variability may have its value in ensuring that part of a bacillary population has adhesive properties and part dispersive properties.

With one doubtful exception (K. 38), all the fimbriate strains possessed one or both of the adhesive properties attributed, respectively, to the MS and MR adhesins, while all the non-fimbriate strains lacked these properties. Many fimbriate cultures also showed a third adhesive property, effective for glass and cellulose, but this was not necessarily dependent on fimbriation, since it occurred to some extent in certain non-capsulate non-fimbriate cultures. It perhaps depended on a hydrophobic state affecting either the fimbriae or the bacillary cell wall. The electrophoretic studies of Brinton et al. (1954) suggest that fimbriae bear a weaker negative charge than the normal bacillary wall. This would assist their approach to negatively-charged substrates.

Only the bacilli which possessed fimbriae with MS adhesin adhered to the highly hydrophilic and negatively charged surfaces of animal blood cells and 'smooth' yeast cells. The specificity of mannose in preventing this adhesion suggests that a chemical group with some relationship to mannose may serve as a specfic receptor for the MS adhesin. This must be a common group which occurs in a wide variety of animal, plant and fungal cells. The presence of MS adhesin in bacilli infecting the animal body would probably hinder their spread by fixing them to tissue cells, and might promote their phagocytosis by attaching them to leucocytes, so nullifying the anti-phagocytic action of the capsule. This would be concordant with the absence of fimbriae from the more pathogenic strains. 
Possession of the MR adhesin enabled attachment to some of the substrates susceptible to the MS adhesin, such as fungus mycelium, 'rough' yeast and plant root hairs. The MR activity, however, is not merely a low grade of the MS activity; its greater effectiveness for tanned ox red cells and its resistance to mannose show that it is due to an agent of different specificity. Similar MR activity was found in ten fimbriate strains of Serratia marcescens, but not in fimbriate strains of Escherichia coli, Aerobacter cloacae, Shigella flexneri and Salmonella spp., which showed only the MS activities. The MR fimbrial adhesin of Klebsiella is not to be confused with the mannose-resistant haemagglutinins found in some fimbriate and non-fimbriate strains of $\boldsymbol{E}$. coli (e.g. nos. 92 and 224, Duguid et al. 1955; Duguid \& Gillies, 1957). The latter can adhere to and agglutinate the fresh untreated red cells of one or a few species (e.g. man, sheep or ox), reacting strongly at $3-5^{\circ}$ and 'eluting' at 20-40 $0^{\circ}$. The klebsiellas do not elute on warming.

The role of fimbriae in saprophytic and commensal bacilli may be to hold them on the surfaces of dead or living animal and plant tissues, such as intestinal epithelium and root hairs, where nutrients become available by lysis, leakage or excretion. Adhesion to the surfaces of mineral solids may assist uptake of nutrient solutes which are concentrated there by adsorption. When the habitat is a stagnant liquid, advantage may accrue from the action of fimbriae in promoting growth as a surface pellicle with better access to atmospheric oxygen.

I wish to thank Dr W. Blyth, Dr J. G. Collee, Dr S. T. Cowan, Dr P. N. Edmunds, Dr P. R. Edwards and Mr A. J. Holding for the supply of strains, materials and information, and Mr G. Wilson for technical assistance.

\section{REFERENCES}

Anderson, T. F. (1949). On the mechanism of adsorption of bacteriophages on host cells. Symp. Soc. gen. Microbiol. 1, 76.

BoYDEN, S. V. (1951). The adsorption of proteins on erythrocytes treated with tannic acid and subsequent haemagglutination by antiprotein sera. J.exp. Med. 93, 107.

Brinton, C. C., Buzzeld, A. \& Lauffer, M. A. (1954). Electrophoresis and phage susceptibility studies on a filament-producing variant of the $E$. coli $\mathrm{B}$ bacterium. Biochim. Biophys. Acta, 15, 533.

Constable, F. L. (1956). Fimbriae and haemagglutinating activity in strains of Bacterium cloacae. J. Path. Bact. 72, 133.

Duguid, J. P. (1948). The influence of cultural conditions on the morphology of Bacterium aerogenes with reference to nuclear bodies and capsule size. J. Path. Bact. 60, 265.

Duguid, J. P. (1951). The demonstration of bacterial capsules and slime. J. Path. Bact. 63, 673.

Duguid, J. P.\& GrLlies, R. R. (1957). Fimbriae and adhesive properties in dysentery bacilli. J. Path. Bact. 74, 397.

Duguid, J. P. \& Gillies, R. R. (1958). Fimbriae and haemagglutinating activity in Salmonella, Klebsiella, Proteus and Chromobacterium. J. Path. Bact. 75, 519.

Duguid, J. P., Smith, I. W., Dempster, G. \& Edmunds, P. N. (1955). Non-flagellar filamentous appendages ('Fimbriae') and haemagglutinating activity in Bacterium coli. J. Path. Bact. 70, 335.

Edmunds, P. N. (1954). Further Klebsiella capsule types. J. infect. Dis. 94, 65. 
EDWARds, P. R. \& EwING, W. H. (1955). Identification of Enterobacteriaceae. Minneapolis: Burgess Publishing Co.

Edwards, P.R. \& Fife, M. A. (1952). Capsule types of Klebsiella. J. infect. Dis. $91,92$.

Gillires, R. R. \& Dugurd, J. P. (1958). The fimbrial antigens of Shigella flexneri. J. Hyg., Camb. 56, 303.

Houwink, A. L. \& vaN ITERson, W. (1950). Electron microscopical observations on bacterial cytology. II. A study on flagellation. Biochim. Biophys. Acta, 5, 10.

Mackie, T. J. \& McCartney, J. E. (1956). Handbook of Practical Bacteriology, 9th ed. pp. 427-9. Edinburgh: E. and S. Livingstone, Ltd.

Titrsler, R. P. \& Sandholzer, L. A. (1936). The use of semi-solid agar for the detection of bacterial motility. J. Bact. 31, 575 .

Wilkinson, J. F. (1958). The extracellular polysaccharides of bacteria. Bact. Rev. 22, 46.

Wilkinson, J. F., Dugurd, J. P. \& Edmunds, P. N. (1954). The distribution of polysaccharide production in Aerobacter and Escherichia strains and its relation to antigenic character. J. gen. Microbiol. 11, 59.

\section{EXPLANATION OF PLATES}

Except where otherwise stated the bacilli were taken from $48 \mathrm{hr}$. cultures in broth at $37^{\circ}$. Figs. 1-7 are dried films shadow-cast with gold-palladium at $15^{\circ}$, shown by the electron microscope $(75 \mathrm{kV})$. Figs. 8-10 are unstained wet films shown by phase-contrast microscope.

\section{Plate 1}

Fig. 1. Klebsiella type 54 (strain A. 3); bacillus with fimbriae and a medium-sized capsule. The capsule is much shrunken by drying and barely visible; it partially obscures the margins of the cell wall and the proximal parts of the fimbriae. $(\times 40,000$.

Plate 2

Fig. 2. Klebsiella type 3 (N. 5047); non-fimbriate bacillus possessing a very large capsule which obscures the outlines of the cell wall. $(\times 27,000$.)

Fig. 3. Shigella flexneri type $2 \mathrm{a}$; non-fimbriate non-capsulate bacillus showing the outlines of its cell wall unobscured; cf. fig. 2 . $(\times 30,000$. $)$

Fig. 4. Non-capsulate mutant of a fimbriate Klebsiella type-54 strain. Note the absence of any obscuring of the cell wall and proximal parts of the fimbriae; cf. fig. 1 . $(\times 40,000$.

\section{Plate 3}

Fig. 5. Bacillus from a $48 \mathrm{hr}$. agar culture of a mutant of non-capsulate strain A. $3(0)$ possessing only MR adhesive activity. It bears scanty fimbriae of the very thin, pliable type associated with MR activity. $(\times 40,000$.)

Fig. 6. Klebsiella type 54 (A. 3); bacillus with fimbriae and a very large capsule, from a $72 \mathrm{hr}$. culture on phosphate-buffered 'excess-sugar' agar medium containing $1 \%$ glucose and $0.1 \%$ peptone. Note the fimbriae passing out through and beyond the capsule. $(\times 28,000$.)

Fig. 7. Klebsiella type 2 (N. 9502); bacillus undergoing fission; one daughter cell is fimbriate and the other non-fimbriate. $(\times 25,000$. $)$

\section{Prate 4}

Fig. 8. Klebsiella type 55 (K. 55); fimbriate bacilli with MS adhesin adhering to and agglutinating guinea-pig leucocytes in wet film. About 25 adherent bacilli are seen; many more were adherent in other focal planes. $(\times 2200$.)

Fig. 9. Klebsiella type 57 (K. 57); fimbriate bacilli with MS and MR adhesins adhering to tip and sides of a root hair of a cress seedling. The wet film was prepared after $\mathbf{5}$ min. exposure of the seedling to the bacilli. $(\times 1300$.)

Fig. 10. Numerous Klebsiella type 26 (K. 26) fimbriate bacilli with MR adhesin adhering to hyphae of Monosporium apiospermum. The few non-adherent bacilli in the wet film give very blurred images due to Brownian movement. $(\times 2000$. $)$ 
Journal of General Microbiology, Vol. 21, No. 1

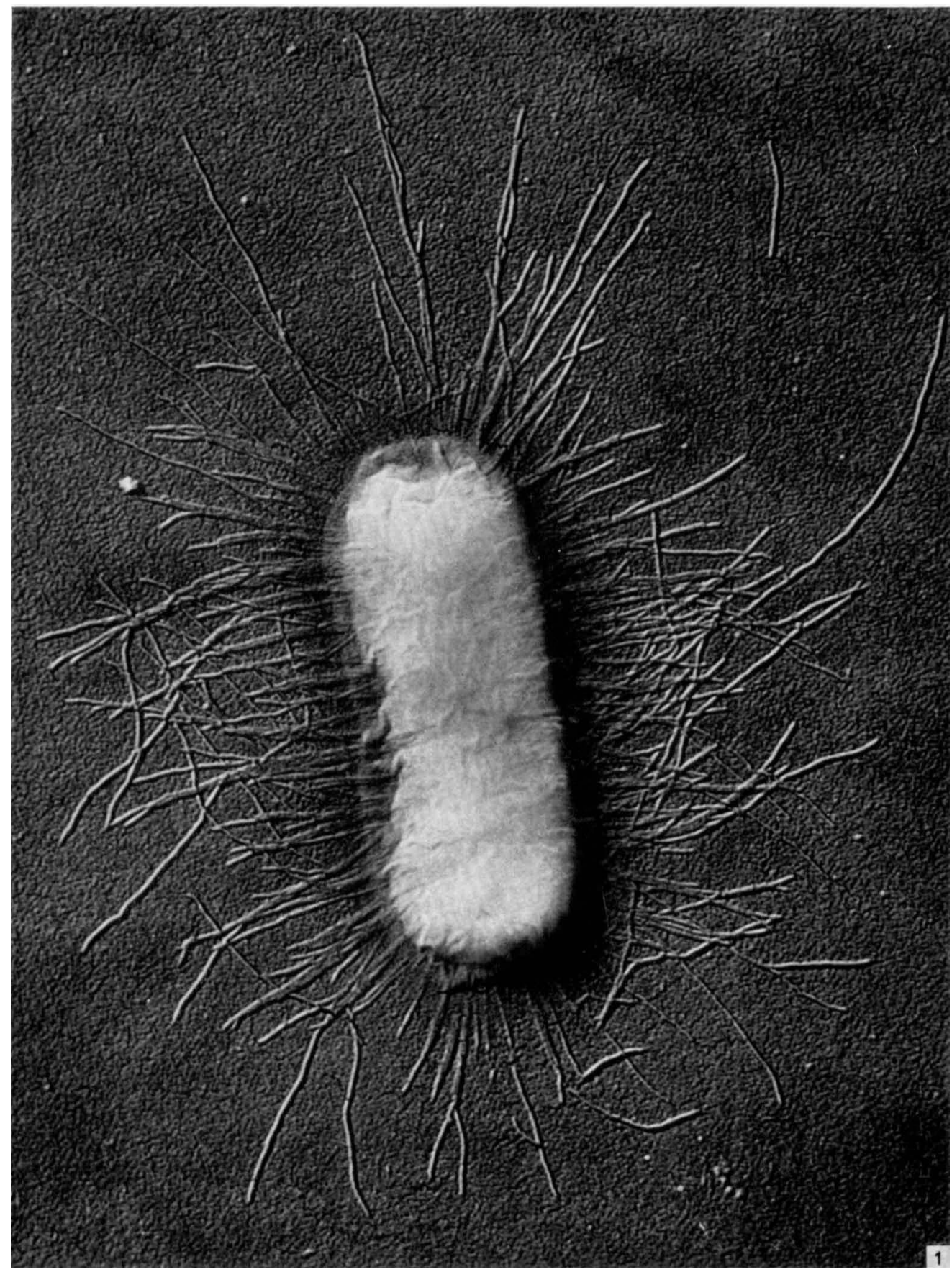

J. P. Degum-Fimbriaf ani abhesivei propertits, Plate 1

(Facing p. 286) 
Journal of General Microbiology, Vol. 21, No. 1
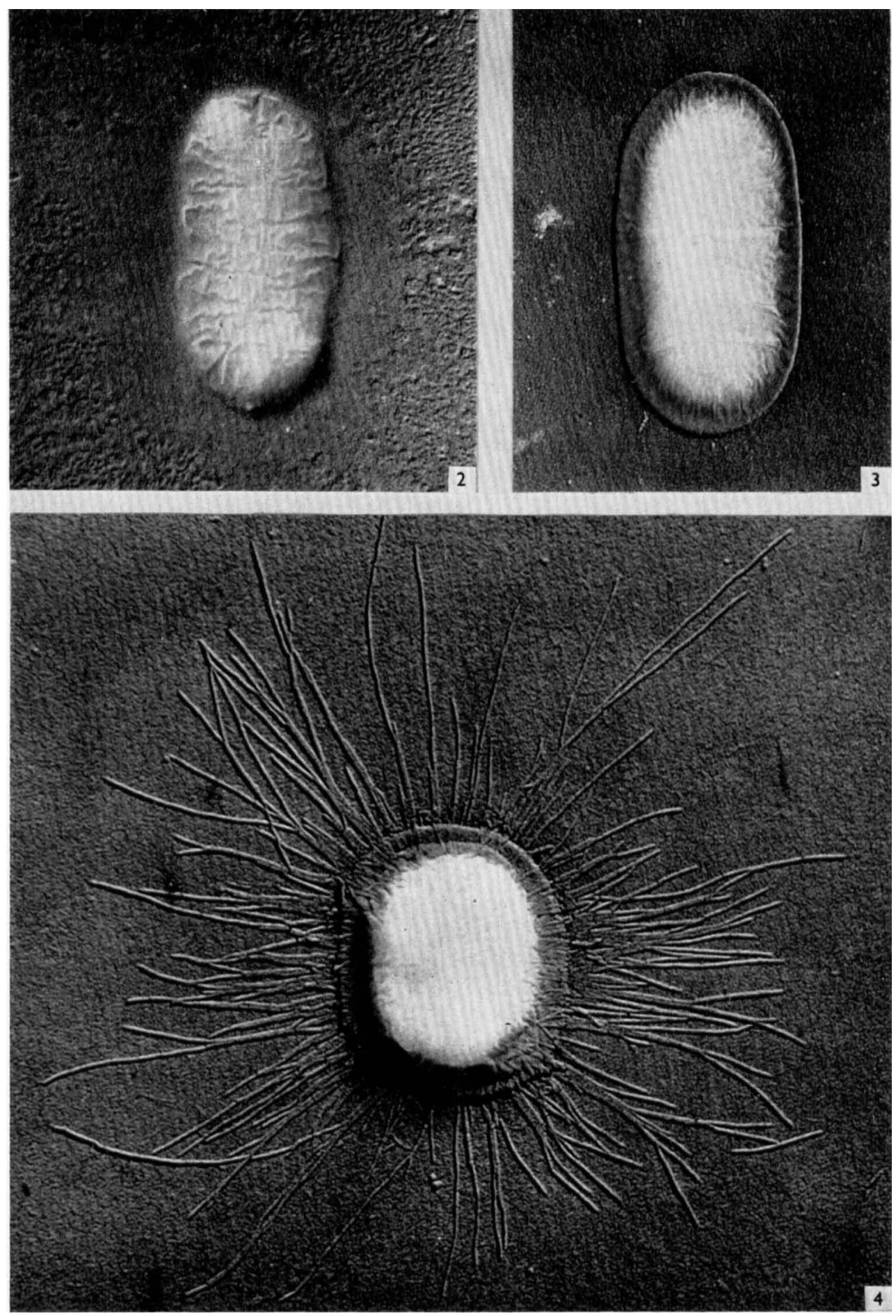

J. P. Duguid-Fimbriae and adhesive properties. Plate 2 
Journal of General Microbiology, Vol. 21, No. 1
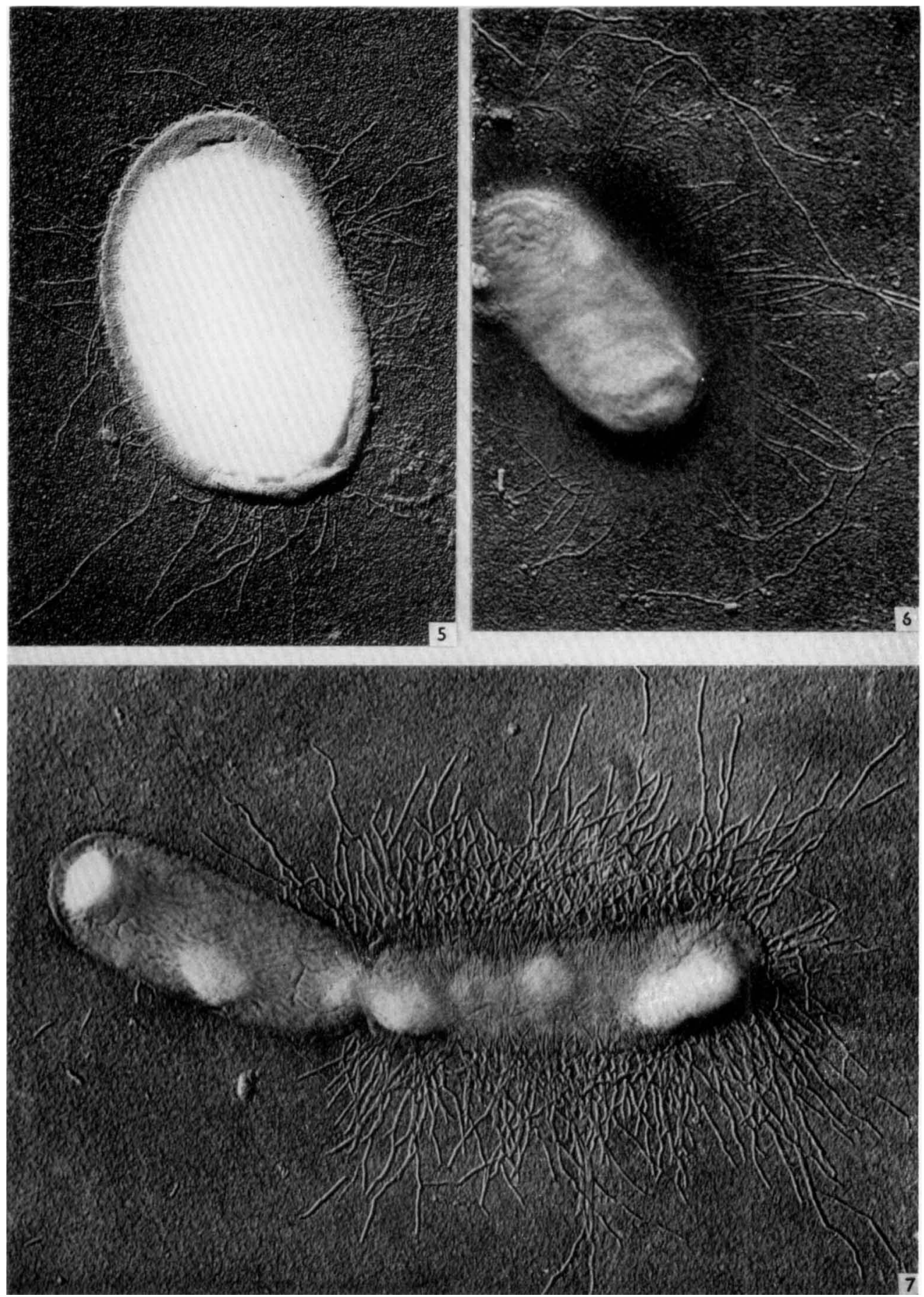

J. P. Duguid-Fimbriat and adhesive properties. Plate 3 
Journal of General Microbiology, Vol. 21, No. 1
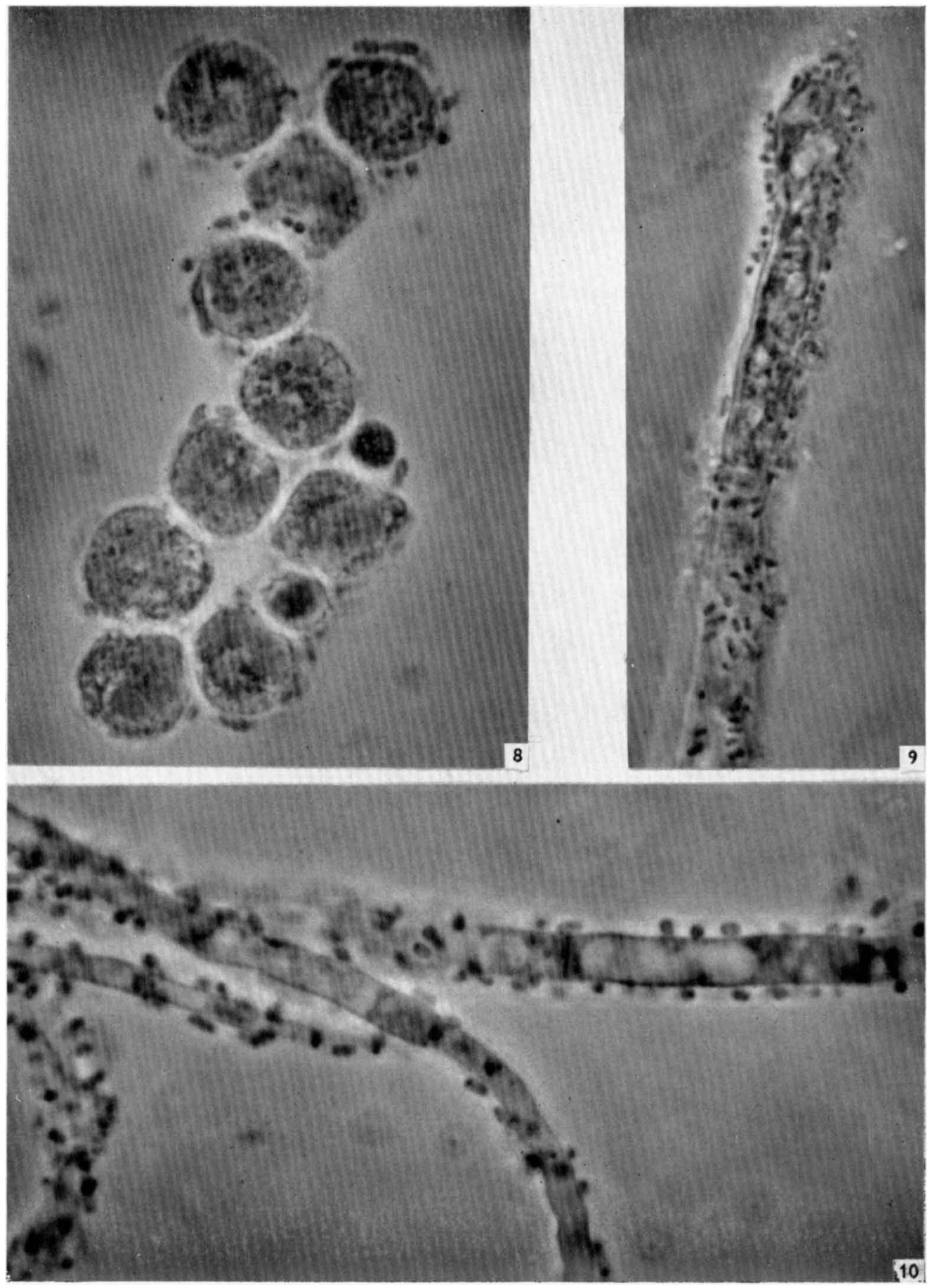

J. P. Duguid-Fimbriae and adhesive properties, Plate 4 